\title{
Strategi Pengembangan Agroforestri Di Kecamatan Pulau Ternate, Kota Ternate
}

\author{
Mahdi Tamrin', Abdul Kamdir Kamaluddin² \\ 1,2 Program Studi Kehutanan, Fakultas Pertanian, Universitas Khairun, Indonesia, \\ Email:adhy.nagkokotu@gmail.com;dul_alzi@yahoo.com
}

\begin{abstract}
Agroforestri is an integrated land use system, which has social and ecological aspects, is carried out through a combination of trees with agricultural crops and or livestock (animals), either in Bersama-sama or in turns, so that from one unit of land can be obtained the results-vegetable and animal products optimally and sustainably. The purpose of this study is (1) See how the pattern of Agroforestry Research in Ternate Island District (2) What strategies are applied by the community in development agroforestry district of Ternate Island. Data retrieval is carried out with field observations directly on the intentionally selected agroforestry land or purposive sampling. Strategic analysis of agroforestry development is conducted using SWOT analysis (strengths, weakness, opportunity and threats). The results showed a score calculation on the matrix of EFAs and IFAS the development of agroforestry in the island of Ternate in the position of the Quadrant II $(0.48 ;-0.27)$. Quadrant II is the situation of farmers in the face of threats, but farmers still have the power in terms of internal strategy that must be applied using the power to exploit the opportunities. Hereinafter determined the chosen strategy as an alternative development namely (1) The socialization of environmental awareness and understanding of the benefits of agroforestry to minimize the occurrence of land conversion (S1, S3, S4, S5, T1, T3, T5), (2) develop agroforestry pattern with the application of technology to increase land productivity and production of high and diverse results (S2, S3, S5, T1, T2, T3, T4, T5) and (3) maintain and improve the quality of agroforestry products (S1, S2, S3, T1, T2, T5).
\end{abstract}

Keywords: Agroforestry, pattern development, strategy

\begin{abstract}
ABSTRAK
Agroforestri merupakan sistem penggunaan lahan terpadu, yang memiliki aspek sosial dan ekologi, dilaksanakan melalui perpaduan antara pepohonan dengan tanaman pertanian dan atau ternak (hewan), baik secara bersama-sama atau bergiliran, sehingga dari satu unit lahan dapat diperoleh hasil-hasil nabati dan hewani secara optimal dan berkesinambungan. Tujuan dari penelitian ini yaitu (1) Melihat bagaimana pola pengembangan agroforestri di Kecamatan Pulau Ternate (2) Strategi apa yang diterapkan masyarakat dalam mengembangkan agroforestri Kecamatan Pulau Ternate. Pengambilan data dilakukan dengan observasi lapangan secara langsung di lahan agroforestri yang dipilih secara sengaja atau purposive sampling. Analisis strategis pengembangan agroforestri dilakukan menggunakan analisis SWOT (strengths, weakness, opportunity dan threats). Hasil penelitian menunjukkan perhitungan skor pada matrik EFAS dan IFAS pengembangan agroforestri di kecamatan Pulau Ternate berada pada posisi kuadran II (0.48;
\end{abstract}




\section{TECHNO: Vol. 09 (02) Oktober 2020}

-0.27). Kuadran II merupakan situasi petani dalam menghadapi ancaman, namun petani masih memiliki kekuatan dari segi internal yaitu strategi yang harus diterapkan dengan menggunakan kekuatan untuk memanfaatkan peluang yang ada. Selanjutnya ditentukan strategi terpilih sebagai alternatif pengembangan yakni (1) sosialisasi kesadaran lingkungan dan pemahaman tentang manfaat agroforestri untuk meminimalisir terjadinya konversi lahan (S1, S3, S4, S5, T1, T3, T5), (2) mengembangkan pola agroforestri dengan penerapan teknologi untuk peningkatan produktivitas lahan dan produksi hasil yang tinggi dan beragam (S2, S3, S5, T1, T2, T3, T4, T5) dan (3) mempertahankan serta meningkatkan kualitas produk agroforestri (S1, S2, S3, $\mathrm{T} 1, \mathrm{~T} 2, \mathrm{~T} 5)$.

Kata Kunci: Agroforestri, Pola Pengembangan, Strategi

\section{PENDAHULUAN}

Sistem agroforestri merupakan bentuk pemanfaatan lahan yang dikembangkan untuk memberikan manfaat sehingga dapat meningkatkan tingkat kesejahteraan masyarakat. Nair (1983) dalam Tamrin (2015) mengatakan bahwa agroforestri adalah sistem penggunaan lahan terpadu, yang memiliki aspek sosial dan ekologi, dilaksanakan melalui perpaduan antara pepohonan dengan tanaman pertanian dan atau ternak (hewan), baik secara bersama-sama atau bergiliran, sehingga dari satu unit lahan dapat diperoleh hasil-hasil nabati dan hewani secara optimal dan berkesinambungan. Umumnya masyarakat mempunyai hubungan erat dengan sumberdaya alam sekitar. Upaya mereka dalam pengelolaan sumberdaya alam yang ada di sekitar mereka selalu berangkat dari pengalaman yang baik terhadap lingkungan sehingga mempunyai daya dukung yang baik terhadap proses pelaksanaannya. Ketergantungan masyarakat terhadap lingkungan dalam hal ini sumberdaya hutan tidak terlepas dari pengetahuan tradisional yang diperoleh secara turun temurun sehingga sumberdaya yang ada di dalamnya masih terus dapat dikelola dan dimanfaatkan secara berkelanjutan (Ariyanto 2014 dan Tamrin, 2015).

Bentuk pengembangan agroforestri yang digunakan bukanlah sistem yang baru bagi masyarakat Pulau Ternate. Masyarakat di Pulau Ternate telah mempraktekkan pola campuran atau agroforestri dengan sebutan khas yaitu Gura. Gura berasal dari bahasa Ternate yang artinya bertanam di kebun. Gura merupakan sistem pengelolaan kebun campuran yang dilakukan secara turun-temurun. Sesungguhnya agroforestri telah dipraktekkan oleh nenek moyang bangsa Indonesia sejak dahulu (Syamsudin el al. 2019). Namun hampir setiap daerah memiliki nama dan sistem pengelolaan tersendiri. Sistem pengetahuan lokal tersebut walaupun berbeda satu sama lain sesuai dengan kondisi sosial budaya dan tipe ekosistem setempat (Riease dan Abdi 2010; Rohadi et al. 2013).

Pengelolaan sumberdaya hutan dewasa ini dihadapkan pada masalah peningkatan jumlah penduduk yang berakibat pada meningkatnya kebutuhan pangan dan lahan (Kamaluddin, 2019). Pendekatan pengelolaan sumberdaya hutan yang senantiasa memperhatikan variabel kondisi objektif masyarakat kepulauan seperti kondisi ekologis, ekonomi dan sosial, sangat diperlukan untuk mengatasi permasalahan tersebut dengan berbagai kajian strategi, khususnya dalam kehidupan masyarakat kepulauan.

Pengembangan agroforestri mempunyai arti penting karena dapat memperluas kesempatan kerja, meningkatkan pendapatan serta diharapkan dapat memberikan sumbangan pendapatan terhadap pendapatan keluarga, maupun pendapatan daerah dan diyakini dapat menjawab tantangan krisis pangan kepulauan (Mayrowani dan Ashari, 2011). Oleh sebab itu, perlu 
adanya strategi pengembangan agroforestri agar usaha masyarakat dapat bertahan dan lebih berkembang.

Permasalahan sosial, tekanan pertumbuhan penduduk yang terus meningkat dari waktu ke waktu dewasa ini, merupakan substansi penting dalam menyoroti keberhasilan atau kegagalan satu pengelolaan sumberdaya hutan dan lahan akibat tingginya ketergantungan masyarakat merupakan satu hal yang tidak terbantahkan karena merupakan satu-satunya sumberdaya yang dapat dijadikan sebagai sumber penghidupan masyarakat dalam menopang keberlanjutan kehidupan masyarakat di wilayah kepulauan dengan sistem pengalihgunaan lahan hutan untuk bercocok tanam.

Pengembangan agroforestri tidak hanya terfokus pada teknik dan biofisik saja akan tetapi diperlukan rumusan kebijakan pemerintah sebagai aturan dalam penggunaan sistem agroforestri juga sangat menentukan perkembangan agroforestri (Indrianti dan Ulfiasih 2018). Pengembangan agroforestri oleh masyarakat Pulau Ternate dilakukan sesuai dengan pengetahuan lokal yang telah ada (Kamaluddin, 2020). Pengetahuan lokal tersebut secara turun temurun dimanfaatkan dan diwariskan masyarakat dalam kehidupan sehari-hari. Foresta et al. (2000) menyatakan bahwa sebaiknya agroforestri dalam bentuk kebun dijadikan sumber inspirasi dan model yang sangat menarik untuk pengembangan pola pertanian dan kehutanan berkelanjutan yang memadukan manfaat ekonomi, sosial, perlindungan, kesuburan tanah, dan pelestarian keanekaragaman hayati. Penelitian ini dilaksanakan untuk menganalisis bentuk pengembangan agroforestri Kecamatan Pulau Ternate dan menyusun strategi untuk pengembangan agroforestri di Kecamatan Pulau Ternate.

\section{METODE PENELITIAN}

Penelitian ini dilaksanakan di Kelurahan Sulamadaha dan Loto Kecamatan Pulau Ternate. Pemilihan lokasi dilakukan secara sengaja atau purposive sampling dengan pertimbangan lokasi tersebut merupakan sentra produksi tanaman pertanian yang dikembangakan dilahan agroforestri komplek.

Data yang digunakan untuk menunjang jalannya penelitian ini adalah data primer dan data sekunder. Data primer diperoleh melalui wawancara mendalam dengan petani pemilik lahan dan pengamatan langsung di lapangan untuk mendapatkan informasi yang lebih detail. Observasi secara langsung merupakan metode pengambilan data lapangan dengan melakukan pencatatan secara teliti terhadap kajian yang diteliti. Observasi lapang dilakukan untuk menentukan lokasi pengumpulan data dan memperoleh data aktual mengenai pola pengembangan agroforestri yang digunakan, serta dilanjutkan dengan wawancara terstruktur terhadap masyarakat dan para pihak terkait.

Analisis strategis pengembangan agroforestri dilakukan dengan menggunakan analisis SWOT (strengths, weakness, opportunity dan threats). Langkah ini dilakukan untuk menganalisis strategi pengembangan agroforestri di Kecamatan Pulau Ternate adalah sebagai berikut:

1. Analisis SWOT (strengths, weaknesses, opportunities, threats) digunakan untuk mengidentifikasi faktor internal dan eksternal secara sistematis.

2. Matriks SWOT merupakan analisis yang menggambarkan secara jelas bagaimana peluang dan ancaman eksternal yang dihadapi dan disesuaikan dengan kekuatan dan kelemahan yang dimiliki masyarakat untuk merumuskan strategi pengembangan. 
3. Matriks SWOT merupakan alat analisis penting yang dapat digunakan dalam mengembangkan empat macam strategi.

Matriks SWOT dibangun berdasarkan hasil analisis faktor-faktor strategis eksternal maupun internal yang disusun empat strategi utama (Rangkuti 2006), yaitu: SO, WO, ST dan WT (Tabel 1.)

Tabel 1. Matrik SWOT

\begin{tabular}{|c|c|c|}
\hline Internal & $\begin{array}{c}\text { STRENGTHS } \\
(S)\end{array}$ & $\begin{array}{c}\text { WEAKNESSES } \\
(W)\end{array}$ \\
\hline \multicolumn{3}{|l|}{ Eksternal } \\
\hline $\begin{array}{c}\text { OPPORTUNITIES } \\
(O)\end{array}$ & $\begin{array}{c}\text { STRATEGI (S-O) } \\
\text { Strategi yang menggunakan } \\
\text { kekuatan untuk memanfaatkan } \\
\text { peluang }\end{array}$ & $\begin{array}{c}\text { STRATEGI (W-O) } \\
\text { Strategi yang meminimalkan } \\
\text { kelemahan untuk memanfaatkan } \\
\text { peluang }\end{array}$ \\
\hline $\begin{array}{c}\text { TREATHS } \\
\quad(T)\end{array}$ & $\begin{array}{c}\text { STRATEGI (S-T) } \\
\text { Strategi yang menggunakan } \\
\text { kekuatan untuk mengatasi } \\
\text { ancaman }\end{array}$ & $\begin{array}{c}\text { STRATEGI }(\mathrm{W}-\mathrm{T}) \\
\text { Strategi } \\
\text { yang meminimalkan } \\
\text { kelemahan dan } \\
\text { menghindari } \\
\text { ancaman } \\
\end{array}$ \\
\hline
\end{tabular}

Sumber: (Hunger dan Wheleen 2003)

Model yang dikembangkan dengan menggunakan matriks faktor strategi internal (IFAS) dan matriks faktor strategi eksternal (EFAS). Masing-masing faktor diberi bobot tertinggi 3,00 untuk yang paling berpengaruh dan 1,00 untuk yang dianggap tidak penting. Rating peubah yang digunakan dimulai dari angka 1 (sangat buruk), 2 (buruk), 3 (baik) dan 4 (sangat baik). Peubah yang paling berpengaruh, adalah peubah yang memiliki nilai pengaruh paling besar dibandingkan dengan nilai pengaruh peubah-peubah lainnya. Klasifikasi faktor dibuat dalam bentuk matriks IFAS dan EFAS.

\section{HASIL DAN PEMBAHASAN}

Pengelolaan dan pengembangan agroforestri di Kelurahan Loto dan Kelurahan Sulamadaha Kecamatan Pulau Ternate masih sangat tradisional, kegiatan ini telah dilakukan sejak dahulu dan masih dipertahankan sampai saat ini oleh petani karena besarnya manfaat yang diperoleh.

\section{Strategi Pengembangan Agroforestri}

Strategi pada umumnya merupakan alat yang digunakan untuk mencapai tujuan (Rangkuti 1997). Perumusan strategi pengembangan agroforestri di Kelurahan Loto dan Kelurahan Sulamadaha, Kecamatan Pulau Ternate disusun berdasarkan variabel yang dirangkum untuk mendapatkan alternatif strategi pengembangan melalui matriks internal-eksternal. Uraian lengkap faktor internal dan eksternal diuraikan sebagai berikut:

\section{Faktor internal}

Analisis faktor internal adalah langkah awal dalam merumuskan strategi pengembangan, analisis ini dilakukan untuk mengidentifikasi faktor-faktor yang menjadi kekuatan dan kelemahan suatu usaha. Hasil identifikasi faktor kekuatan dan kelemahan yang dimiliki suatu 
usaha dapat digunakan sebagai dasar penetapan strategi pengembangan usaha sehingga peluang dapat dimanfaatkan dengan baik (Rangkuti 1997 dalam Tamrin, 2015). Identifikasi ke lokasi dengan melibatkan beberapa expert yang dianggap mengetahui tentang pengelolaan agroforestri, penilaian bobot dan rating faktor internal ditampilkan pada matriks faktor strategi internal.

Hasil analisis faktor internal pengembangan agroforestri di Kelurahan Loto dan Sulamadaha terdapat 5 faktor kekuatan dan 5 faktor kelemahan. Berikut dicantumkan strategi faktor internal pada Tabel 2.

Tabel 2. Strategi Faktor Internal

\begin{tabular}{|c|c|c|c|}
\hline Variabel & Bobot & Rating & Skor \\
\hline \multicolumn{4}{|l|}{ Kekuatan } \\
\hline 1. Modal pengelolaan cukup rendah & 0.12 & 4 & 0.48 \\
\hline 2. Produk yang dihasilkan berkualitas & 0.11 & 3 & 0.30 \\
\hline 3. Tersedianya tenaga kerja & 0.18 & 4 & 0.72 \\
\hline 4. Kearifan lokal yang masih dipertahankan & 0.13 & 3 & 0.39 \\
\hline 5. Jaminan tabungan bagi rumah tangga & 0.11 & 4 & 0.44 \\
\hline Total & & & 2.33 \\
\hline \multicolumn{4}{|l|}{ Kelemahan } \\
\hline 1. Keterbatasan informasi dan akses & 0.11 & 4 & 0.44 \\
\hline 2. Keterbatasan teknologi & 0.11 & 3 & 0.33 \\
\hline 3. Minimnya pengetahuan petani tentang Agroforestri & 0.12 & 3 & 0.36 \\
\hline 4. Minimnya dukungan pemerintah & 0.11 & 3 & 0.33 \\
\hline Total & & & 1.85 \\
\hline
\end{tabular}

\section{Faktor eksternal}

Analisis faktor eksternal ditujukan untuk mengidentifikasi faktor-faktor yang menjadi peluang dan ancaman yang dihadapi petani. Peluang merupakan suatu usaha yang dibangun secara menguntungkan sedangkan ancaman adalah tantangan yang timbul karena adanya perubahan lingkungan yang dapat mengurangi keuntungan suatu usaha (Kotler 2002).

Tabel 3. Strategi Faktor Eksternal

\begin{tabular}{llll}
\hline Variabel & Bobot & Rating & Skor \\
\hline Peluang & & & 0.51 \\
\hline 1. Pendampingan LSM & 0.17 & 3 & 0.75 \\
\hline 2. Terbukanya pasar/swalayan & 0.25 & 3 & 0.33 \\
\hline 3. Kerjasama dengan mitra rumah makan & 0.11 & 3 & 0.57 \\
\hline 4. Meningkatnya permintaan hasil produksi & 0.19 & 3 & 2.16 \\
\hline \multicolumn{2}{l}{ Total } & & \\
\hline Ancaman & & & 0.52 \\
\hline 1. Konversi lahan & 0.13 & 4 & 0.80 \\
\hline 2. Hama dan penyakit & 0.16 & 3 & 0.45 \\
\hline 3. Pertambahan penduduk & 0.15 & 3 & 0.36 \\
\hline 4. Abu Vulkanik & 0.12 & 3 & 0.30 \\
\hline 5. Perubahan musim yang tidak menentu & Total & 0.11 & 3 \\
\hline
\end{tabular}




\section{Analisis Matrik Internal dan Eksternal}

Pemilihan alternatif strategi yang sesuai dengan kondisi yang ada dengan membuat matriks SWOT. Matriks SWOT dibangun berdasarkan hasil analisis faktor-faktor strategis eksternal maupun internal yang disusun empat strategi utama yaitu: SO, WO, ST dan WT (Tabel 4).

Perhitungan skor pada matrik EFAS dan IFAS pengembangan agroforestri di kecamatan Pulau Ternate berada pada posisi kuadran II $(0.48 ;-0.27)$. Kuadran II merupakan situasi petani dalam menghadapi ancaman, namun petani masih memiliki kekuatan dari segi internal yaitu strategi yang harus diterapkan dengan menggunakan kekuatan untuk memanfaatkan peluang yang ada.

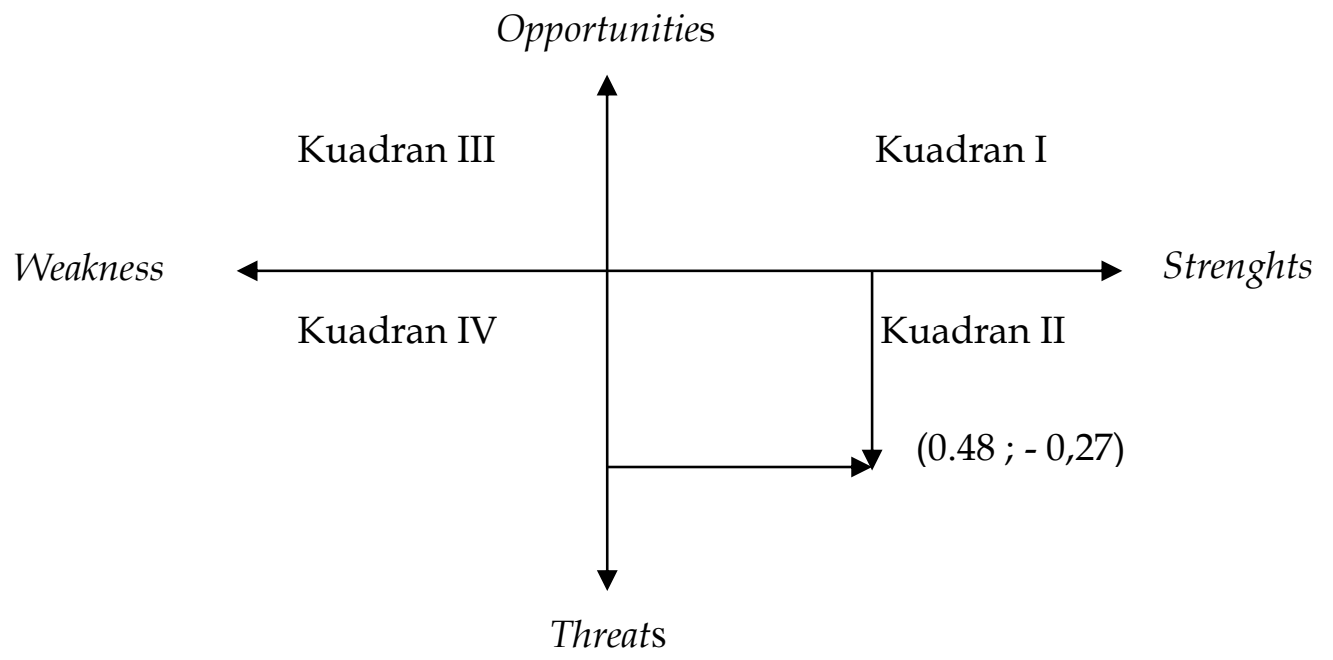

Gambar 1. Diagram SWOT

Tabel 4. Matrik SWOT strategi pengembangan agroforestri di Kecamatan Pulau Ternate

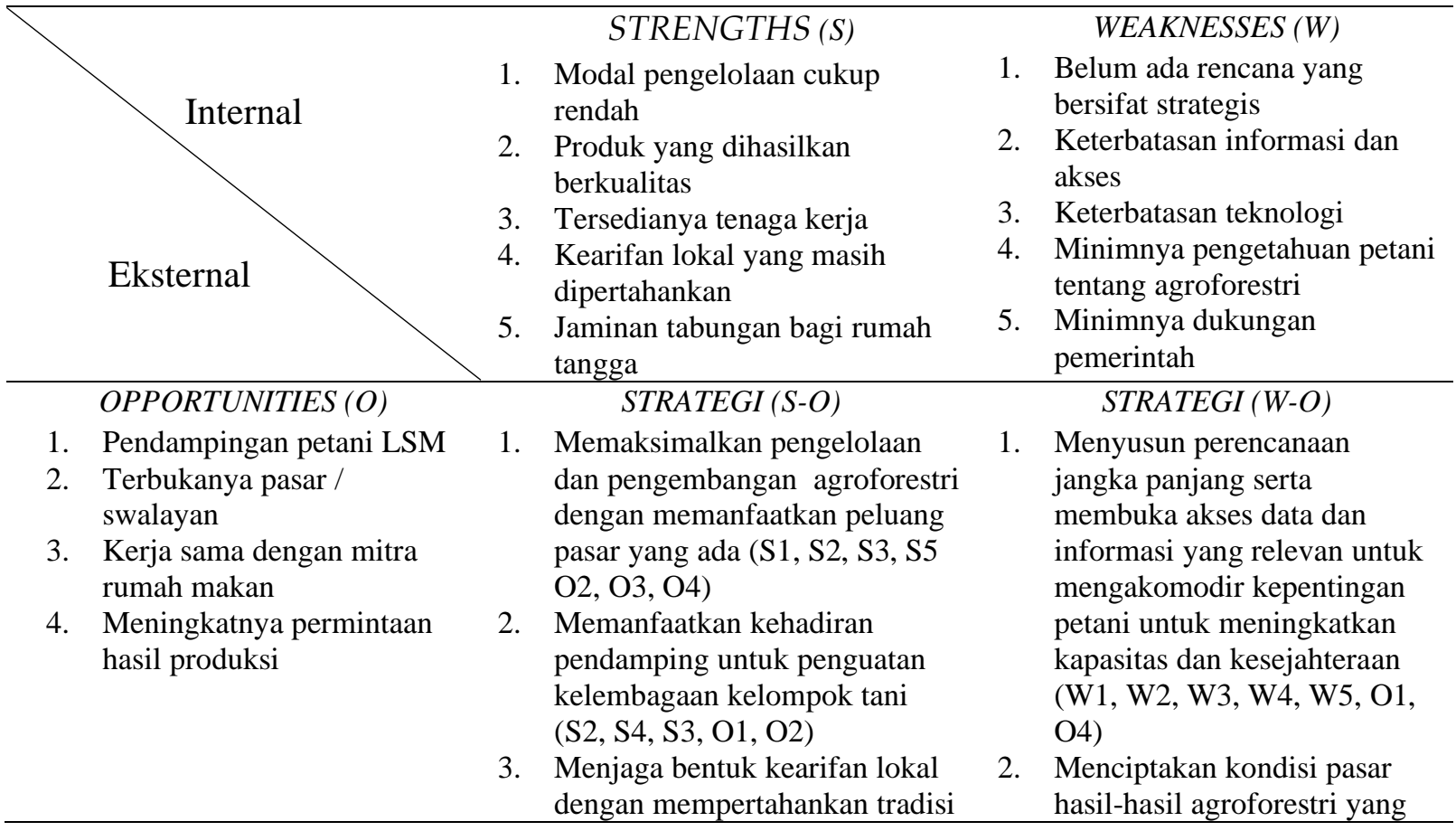




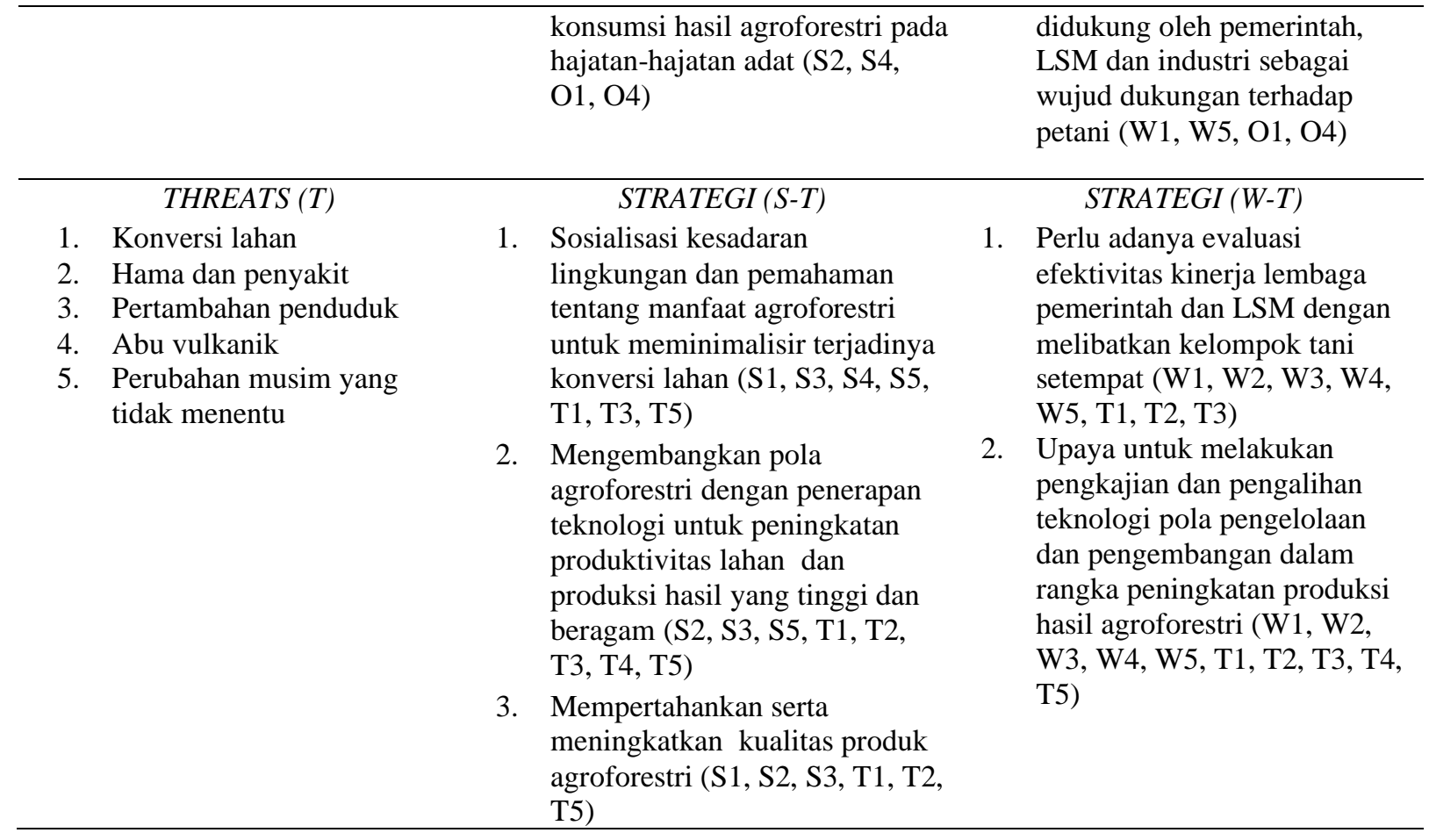

\section{Alternatif Strategi Pengembangan Agroforestri di Kecamatan Pulau Ternate}

1. Sosialisasi kesadaran lingkungan dan pemahaman tentang manfaat agroforestri untuk meminimalisir terjadinya konversi lahan (S1, S3, S4, S5, T1, T3, T5)

Masalah lingkungan merupakan suatu fenomena besar yang memerlukan perhatian khusus dari semua pihak. Untuk mewujudkan itu maka diperlukan berbagai cara, seperti sosialisasi dan aksi nyata dengan melibatkan berbagai unsur. Terlepas dari sosialisasi lingkungan, masyarakat perlu diberi pemahaman tentang manfaat agroforestri. Agroforestri bertujuan untuk mempertahankan jumlah dan keragaman produksi lahan, sehingga dapat memberikan manfaat sosial, ekonomi dan lingkungan bagi para pengguna lahan (Indriyanto 2008).

2. Mengembangkan pola agroforestri dengan penerapan teknologi untuk peningkatan produktivitas lahan dan produksi hasil yang tinggi dan beragam (S2, S3, S5, T1, T2, T3, T4, T5)

Melihat kenyataan sempitnya sumber daya lahan di Kota Ternate menyerukan pemerintah untuk memberikan akses kelola lahan kepada masyarakat untuk mengelola dan meningkatkan hasil produksi. Untuk mewujudkan itu, maka perlu mengembangkan pola agroforestri modern dengan penerapan teknologi untuk peningkatan profuktivitas lahan dan hasil-hasil pertanian dan perkebunan.

3. Mempertahankan serta meningkatkan kualitas produk agroforestri (S1, S2, S3, T1, T2, T5)

Kualitas produksi yang dihasilkan petani sangat baik, hal ini terlihat pada proses pengolahan yang dilakukan petani dari penanaman hingga pemanenan sangat baik. Pada umumnya petani menggunakan kompos sebagai pupuk organik, pembuatan kompos dilakukan oleh petani sendiri dengan menggunakan serasah dan sampah rumah tangga yang bersumber dari lingkungan masyarakat. Kompos merupakan hasil pelapukan bahan 


\section{TECHNO: Vol. 09 (02) Oktober 2020}

bahan organik yang berasal dari tumbuh-tumbuhan ataupun dari kotoran hewan (Bahri, et al 2020)

\section{KESIMPULAN}

1. Pengembangan agroforestri di Kelurahan Loto dan Kelurahan Sulamadaha Kecamatan Pulau Ternate dilakukan secara tradisional dan masih dipertahankan sampai saat ini oleh petani karena besarnya manfaat yang diperoleh.

2. Berdasarkan pada perhitungan skor matrik EFAS dan IFAS pengembangan agroforestri di kecamatan Pulau Ternate berada pada posisi kuadran II $(0.48 ;-0.27)$. Kuadran II menggambarkan situasi petani dalam menghadapi ancaman, namun petani masih memiliki kekuatan dari segi internal.

\section{UCAPAN TERIMA KASIH}

Penelitian ini didanai oleh DIPA Unkhair 2018. Kami berterima kasih kepada Ketua Kelompok Tani Kelurahan Loto dan Sulamadaha. Kami juga berterima kasih kepada Dr. Sri D.A.S dan Dr. Suratman Sujud atas komentar yang sangat memperbaiki naskah penelitian kami.

\section{DAFTAR PUSTAKA}

Ariyanto, Rachman, I., Toknok, B. 2014. Kearifan Masyarakat Lokal Dalam Pengelolaan Hutan Di Desa Rano Kecamatan Balaesang Tanjung Kabupaten Donggala. Warta Rimba Jurnal Ilmiah Kehutanan. 2 (2) 84-91.

Bahri, S., Novianto, Sumini, Holidi, Ibrahim, W. 2020. Pemanfaatan Limbah Pertanian Menjadi Biochar Dan Kompos Sebagai Amelioran Tanah. Jurnal ADIMAS

Foresta H.D, Kusworo A, Michon G, Djatmiko W. 2000. Ketika Kebun Berupa Hutan: Agroforestri Khas Indonesia Sebuah Sumbangan Masyarakat. Bogor: World Agroforestry Centre (ICRAF).

Hunger, D dan Wheelen L. Thomas. 2003. Management Strategis; Alih Bahasa Julianto Agung S. SE., S. Kom. Edisi II Yogyakarta.

Indriyanto. 2008. Pengantar Budidaya Hutan. Jakarta (ID); Bumi Pustaka.

Indrianti, M.A, Ulfiasih. 2018. Implementasi Sistem Agroforestri Sebagai Solusi Pertanian Berkelanjutan Di Gorontalo. Seminar Nasional Fakultas Pertanian Univ. Ichsan Gorontalo.

Kamaluddin, A.K Tamnge., T, Tamrin M. (2020). Contribution of Agroforestry to the Plant Communities and Community Welfare in Ternate. Proceedings of the 5th International Conference on Food, Agriculture and Natural Resources (FANRes 2019). Advances in Engineering Research Vol. 194. 23-25. doi:https://doi.org/10.2991/aer.k.200325.005

Kamaluddin, A.K., Tamrin, M Pemberdayaan Masyarakat Berbasis Potensi Lokal Melalui Skema Perhutanan Sosial Di Area KPH Ternate-Tidore. Jurnal Techno. 08 (02) 308-317. doi: http://dx.doi.org/10.33387/tk.v8i2.1350

Kolter, P. 2002, Manajemen Pemasaran, Edisi Milenium, Jilid 2, PT. Prenhallindo. Jakarta

Mayrowani, H., Ashari. 2011. Pengembangan Agroforestry Untuk Mendukung Ketahanan Pangan dan Pemberdayaan Petani Sekitar Hutan. Pusat Sosial Ekonomi dan Kebijakan Pertanian. 29 (2) 83-98. doi: 10.21082/fae.v29n2.2011.83-98

Syamsudin, Aryadi, M., Prihatiningtyas, E. 2019. Kontribusi Pendapatan Masyarakat Dari Sistem Agroforestri Di KHDTK Unlam (Studi Kasus Di Desa Mandiangin Barat Kabupaten Banjar Kalimantan Selatan). Jurnal Sylva Scienteae. 2 (3) 519-528 
Tamrin, M, A.K. Kamaluddin. 2020. Agroforestry, pattern development, strategy

Rangkuti F. 1997. Analisis SWOT Teknik Membedah Kasus Bisnis, Reorientasi Konsep Perencanaan Strategis Untuk Menghadapi Abad 21. Jakarta. PT Gramedia Pustaka Utama 2006. Analisis SWOT: Teknik Membedah Kasus Bisnis, Jakarta (ID): PT Gramedia Utama.

Riease U, Abdi. 2010. Agroforestri: Solusi Sosial dan Ekonomi Pengelolaan Sumber Daya Hutan. Bandung (ID): Alfabeta

Rohadi D, Herawati T, Firdaus N, Maryani R, Permadi P. 2013. Strategi Nasional Penelitian Agroforestri 2013 - 2030. Bogor, Indonesia.

Tamrin M, Sundawati L, Wijayanto N. 2015. Strategi Pengelolaan Agroforestri Berbasis Aren di Pulau Bacan Kabupaten Halmahera Selatan. Jurnal Kebijakan Strategis Bidang Pertanian dan Lingkungan. Vol. 2 (3). 243-253. doi: https://doi.org/10.29244/jkebijakan.v2i3.12577 